\title{
Profiles of Adversity and Resilience Resources: A Latent Class Analysis of Two Samples
}

*Robin L. J. Lines ${ }^{1,2}$, Monique Crane ${ }^{3}$, Kagan J. Ducker ${ }^{1}$, Nikos Ntoumanis ${ }^{2,4}$, Cecilie Thøgersen-Ntoumani ${ }^{2,4}$, David Fletcher ${ }^{5}$, and Daniel F. Gucciardi ${ }^{1,2}$

\author{
${ }^{1}$ School of Physiotherapy and Exercise Science, Curtin University \\ ${ }^{2}$ Physical Activity and Well-Being Lab, Curtin University \\ ${ }^{3}$ School of Psychology, Macquarie University \\ ${ }^{4}$ School of Psychology, Curtin University \\ ${ }^{5}$ School of Sport, Exercise and Health Sciences, Loughborough University
}

Author Notes

Robin Lines was supported by a Faculty of Health Sciences International Research Scholarship. Daniel Gucciardi was supported by a Curtin Research Fellowship.

*Address correspondence to Robin Lines, School of Physiotherapy and Exercise Science, Curtin University, GPO Box U1987, Western Australia, 6845. Phone: +61 892663653. Email: robin.lines@ postgrad.curtin.edu.au

Lines, R.L.J., Crane, M., Ducker, K.J., Ntoumanis, N., Thøgersen-Ntoumani, C., Fletcher, D., $\&$ Gucciardi, D.F. (in press). Profiles of adversity and resilience resources: A latent class analysis of two samples. British Journal of Psychology. doi: 10.1111/bjop.12397 


\begin{abstract}
Adversities refer to events that are characterised by perceived or actual threat to human functioning. Often considered deleterious for health and well-being, recent work supports an alternative picture of the effects of adversity on human functioning, such that a moderate amount of adversity - when compared with none or high levels - can be beneficial. We extend this body of work in the current study by considering the breadth or type of adversities experienced simultaneously (referred to as polyadversity), with a focus on individual profiles of lifetime adversities. Latent class analysis was employed to explore different configurations of lifetime adversity experiences in two independent samples, and examine how these latent classes differed with regard to resilience resources (i.e., optimism, hope, self-efficacy, and bounce-back ability). University students $(\mathrm{N}=348)$ and members from the broader community $(\mathrm{N}=1506)$ completed measures of lifetime adversity exposure and resilience resources. Three polyadversity classes were revealed in each sample, with both producing a high and a low polyadverstiy class. The third class differed between samples; in the student sample this class represented experiences of vicarious adversity, whereas in the community sample it represented moderate levels of exposure to adversity. Support for the adaptive nature of a moderate amount of adversity exposure was found in the community sample but not in the student sample. This study produces initial evidence of how lifetime adversity experiences group together and how class membership is related to resilience resources.
\end{abstract}

Keywords: resilience, adversity, psychological capital, latent class analysis 


\section{Profiles of Adversity and Resilience Resources: A Latent Class Analysis of Two}

\section{Samples}

Bad things can and do happen to people; whether it is being struck down by serious illness, being exposed to a natural disaster, or experiencing the death of a loved one, most if not all people will experience one or more of these highly aversive events during their lives. Adversities refer broadly to "negative life circumstances that are known to be statistically associated with adjustment difficulties" (Luthar \& Cicchetti, 2000, p. 858). Epidemiological studies show the worldwide prevalence rates of exposure to lifetime adversities to be relatively high. For example, in a study covering 24 countries over six continents, $70.4 \%$ of respondents $(\mathrm{N}=68,894)$ reported experiencing at least one traumatic event, with $30.5 \%$ reporting four or more different events (Benjet et al., 2016). National rates varied between 28.6\% (Bulgaria) and 84.6\% (Ukraine). The most commonly experienced traumatic events included unexpected death of a loved one (31.4\%), witnessing death, a dead body or someone seriously injured (23.7\%), and being mugged (14.5\%). In general, adversity and potentially traumatic events (PTE's) ${ }^{1}$ are statistically associated with various negative psychological and physiological health outcomes such as depression (Burns, Lagdon, Boyda, \& Armour, 2016), posttraumatic stress disorder (Burns et al., 2016; Cavanaugh, Martins, Petras, \& Campbell, 2013), and substance abuse (Armour \& Sleath, 2014; Young-Wolff et al., 2013). Research within the field of stress and adversity usually focuses on these and other deleterious outcomes. However, not everyone who experiences adversity is afflicted with such negative consequences (e.g., Bonanno, Westphal, \& Mancini, 2011).

Different theories suggest that, in the right amount, exposure to stressors or adversities may actually foster resilience. For example, Dienstbier's proposed theory of

\footnotetext{
${ }^{1}$ We acknowledge that events are termed traumatic when they involve perceived or real threat to one's or another person's life or limb (American Psychiatric Association, 2013). Here we use the term adversity to capture the breadth of possible events that might disrupt the functioning of a system, yet adopt traumatic where appropriate (e.g., study cited focused solely on traumatic events).
} 
toughness $(1989,1992)$ postulates that exposure to stress can have a toughening effect when this exposure is limited and there is opportunity for recovery. Similar concepts to toughness have been referred to as stress inoculation (i.e., Meichenbaum, 1976, 1977), steeling (e.g., Rutter, 1987), and immunization (e.g., Başoğlu et al., 1997). A common theme among these perspectives is that exposure to moderate amounts of stress/adversity that are sufficiently challenging to be successfully coped with creates an opportunity for an individual to develop resources (e.g., self-efficacy) which will help them cope with future adversities. Indeed, it has been suggested that to develop the resilience necessary for high performance, individuals may first need to be vulnerable to adversity to subsequently benefit from the psychological and behavioral changes that only this level of trauma can bring (Fletcher, 2018; Fletcher \& Sakar, 2016). In this view toughness can be seen as analogous to physical fitness, in that improvement in physical fitness requires physical exertion followed by a period of recovery to build one's capacity. Though too much exposure to stressors can have debilitating effects on toughness just as overtraining can for physical fitness (Seery, Leo, Lupien, Kondrak, \& Almonte, 2013). This developed toughness is also proposed to be transferable to other domains, both familiar and novel, which has positive implications for resilience to future adversity (Seery \& Quinton, 2016). Toughening may occur via self-reflection, whereby exposure to adversity offers the opportunity to reflect on one's initial response to a stressor and develop resilient capacities (e.g., coping resources) that maximise the likelihood of resilience to future events (Crane, Searle, Kangas, \& Nwiran, 2018). Furthermore, similar to the previously mentioned concepts, this reflective process is most effective during moderate exposure to adversity (Crane et al., 2018). Therefore, moderate levels of adversity offer more opportunity to systematically self-reflect than experiencing no or high levels of adversity, resulting in the strengthening of resilience to future adversities. 
Over the last twenty years there has been a surge of interest examining psychological resilience, and with this numerous definitions have been presented leading to debate around a universally accepted definition (Bonanno, Romero, \& Klein, 2015). We ascribe to the view that resilience is a system's (e.g., individual, team) trajectory of functioning over time within the context of adversity exposure, whereby the system (e.g., individual, team) might withstand the potentially negative effects, or bounce back quickly to normal (i.e., preadversity) or healthy levels of functioning (e.g., Fletcher, 2018; Gucciardi et al., 2018). This conceptualisation helps clarify the distinction between resilience resources (often referred to as protective factors), processes, and outcomes. Resources help maximise the likelihood of a system withstanding or bouncing back from the negative effects of adversity exposure, whereas processes reflect the translation of one's potential for action via cognitive, emotional, or behavioural mechanisms into a demonstrable outcome. Thus, resilience as an emergent outcome is displayed when salient resources are activated in response to an adverse event to enact adaptive processes that result in optimal functioning either in terms of withstanding the negative effects of the adversity or bouncing back from deteriorations in functioning.

Broadly speaking, resilience resources encompass individual (e.g., personality, biological), community (e.g., social support), and societal (e.g., health and social services) factors (Masten, 2011; Windle, 2012). Our focus on individual resources in the current study was informed by a recent conceptual and methodological review of resilience measures that are designed to operationalise such resources (Pangallo, Zibarras, Lewis, \& Flaxman, 2015). The Psychological Capital Questionnaire (PsyCap; Luthans, Youssef, \& Avolio, 2007) received the highest rating of 17 resilience measures reviewed against seven quality assessment criteria, namely theory formulation, internal consistency, replicability, convergent validity, discriminant validity, and application. PsyCap, which is designed to assess four 
resilience resources, was awarded maximum marks in all but one criteria (replicability). First, the resilience component assesses one's ability to bounce back or recover from stress or adversity. The other three resources of hope, self-efficacy, and optimism share a commonality in that they are related to one's thoughts and beliefs about the attainment of future positive states (Feldman et al., 2015). Hope refers to a cognitive process of selfdetermined motivation towards personally valued objectives and ways by which to achieve them (Snyder et al., 2002). Self-efficacy is defined as a belief in one's ability to accomplish a desired goal; these beliefs instil individuals with the motivation to face new challenges and persist in the face of barriers (Bandura, 1997). Finally, optimism reflects an individual's expectancy that positive things will happen (Scheier, Carver, \& Bridges, 1994). Each of these concepts have gained substantial support as key resilience resources across a broad range of samples and contexts (e.g., Chmitorz et al., 2018; Fletcher, 2018). Together, these beliefs can influence behaviours towards a goal, in turn affecting achievement of goals and one's psychological well-being (Rand, Martin, \& Shea, 2011). As beliefs are largely founded in experience, encountering many difficulties (adversities) that are perceived as overwhelming may lead to formation of a belief that we have low agency in the world. In contrast, if we overcome something then we may believe that we are able to overcome difficulties. Thus, forming positive beliefs about your efficacy to overcome demands may be challenging unless you have experienced such adversities. Therefore, the experience of adversities may help one to develop adaptive beliefs through these examined resources.

Scholars have examined the effects of exposure to lifetime adversities on resilience outcomes across various life contexts and indices of functioning (Höltge, McGee, Maerker, \& Thoma, 2018). For example, Seery, Holman, and Silver (2010) found a U-shaped association between the number of lifetime adversities experienced and mental health and well-being. Specifically, individuals who had been exposed to some adversity reported better mental 
health and well-being (e.g., lower global distress, and higher life satisfaction) than people who had experienced either no ( 0 adversities) or high levels (Mean+1SD) of lifetime adversity. In a sub-sample of sufferers of chronic back pain, individuals who had experienced some lifetime adversity (just below the logarithmic mean of 2.22 ; raw score median $=9$ lifetime adverse events) reported lower levels of functional impairment (i.e., extent to which mental/physical health affected social/work activities) and use of health care than people who had experienced either no or high levels of adversity (defined as + 1 SD [.73] above the logarithmic mean of 2.22; Seery, Leo, Holman, \& Silver, 2010). These findings have also been supported in response to laboratory stressors requiring passive endurance and active instrumental performance, in student samples (Seery et al., 2013). In Seery and colleagues' research, lifetime adversities were operationalised using a cumulative measure (i.e., a score of 4 could represent 4 different adversities or the same adversity 4 times). Recent work has differentiated between cumulative acute and chronic adversities, and found that breast cancer survivors who experienced moderate levels of acute lifetime adversities (i.e., time limited events, e.g., death of a loved one) reported higher levels of positive affect and fewer cancerrelated intrusions (i.e., intrusive thoughts, nightmares, intrusive feelings, and imagery) than survivors who had experienced either low or high levels of acute adversities (Dooley, Slavich, Moreno, \& Bower, 2016). Taken together, these findings provide evidence that moderate exposure to adversities may help protect individuals from the negative psychological effects of future stressors/adversities via the selection and development or refinement of resilience resources.

Though research has examined how different degrees of adversity exposure affects functioning, less attention has been paid to how adversities may cluster together (Holt et al., 2017). Considering multiple types of adversities in tandem allows for an examination of differing combinations of adversity experiences, and how such distinct typologies might be 
differentially associated with various indicators of functioning. For example, multiple adversities can better predict outcomes, such as college adjustment (Elliott, Alexander, Pierce, Aspelmeier, Richmond, 2009) and trauma symptoms (Finkelhor, Ormrod, \& Turner, 2007), than single adversities in isolation. The term 'polytraumatisation' (Gustafsson, Nilsson, \& Svedin, 2009) was developed to represent this notion of exposure to multiple types of adversities, rather than repeated instances of single or chronic adversity. Compared to a single or repeated instance of the same adversity, polytraumatisation has a negative effect on mental and physical indices of health (e.g., Briere, Agee, \& Dietrich, 2016; Finkelhor et al., 2007; Gustafsson et al., 2009, Hughes et al., 2017).

To study polytraumatisation or, in the current study 'polyadversity', a person-centred approach is required to identify homogenous groups of individuals based on their adversity experiences. For the assessment of polyadversity classes Latent Class Analysis (LCA) is considered to be an optimal statistical method (Contractor, Caldas, Fletcher, Shea, \& Armour, 2018). Unlike variable-centred approaches (e.g., regression), in LCA the sample is organised into a finite number of meaningful latent subgroups comprised of individuals who have similar response patterns on a set of variables, yet maximises differences between these individuals with people assigned to other clusters (Lanza \& Cooper, 2016). Simply put, there is a focus on the similarities and differences amongst people, rather than associations between variables. In LCA individuals are probabilistically assigned to classes based on the probability of their membership in all identified classes (Berlin, Williams, \& Parra, 2014), often with no a priori decisions about the number of classes, though decision making is led by theory and evidence (Holt et al., 2017). Past work focused on classes of trauma experiences among adult samples has underscored the importance of person-centred analyses. Contractor et al. (2018) identified nine studies via a systematic search of the literature, and found three common types of trauma profiles across this work: individuals who had experienced low or 
high counts of trauma, and specific types of traumas (e.g., childhood maltreatment). These trauma groupings differed on a range of mental health indicators (e.g., depression), with the high trauma class characterised by the poorest degree of mental health.

Though some research has utilised LCA to examine associations of polyadversity class membership with indicators of resilience outcomes such as depression, anxiety, and posttraumatic stress disorder (e.g., Burns et al., 2016; Holt et al., 2017; Young-Wolff et al., 2013), there has been little consideration of the associations between polyadversity class membership and resilience resources or determinants. As resilience involves adjustment to adversity, it is important to understand how polyadversity classes are associated with resilience resources, which in turn may affect an individual's response to future adversities. To do so, we used a person-centred approach to explore polyadversity in two samples (student and community), and examined how the identified classes differ with regard to individual-level resilience resources (i.e., optimism, hope, self-efficacy, and bounce-back ability). In accordance with the findings of a recent meta-analysis of studies utilising personcentred analyses for polytraumatisation class analyses (Contractor et al., 2018), we hypothesised that we would find a class characterised by a higher likelihood to have experienced most or all of the assessed adversities (H1), a class characterised by a lower likelihood of experiencing most or all of the assessed adversities (H2), and a class/classes characterised by a high likelihood of experiencing a specific adversity (H3). We also hypothesised that individuals who have experienced moderate levels of polyadversity (relative to the other classes identified) will report higher levels of individual-level resilience resources when compared to those who have experienced no/low or high levels of polyadversity (H4).

\section{Study 1}

\section{Methods}




\section{Participants}

A convenience sample of 348 undergraduate university students ( $61.5 \%$ female) aged $18-52$ years (mean \pm SD; $22.09 \pm 4.97$ ) was recruited from universities in Western Australia (77\%) and the United Kingdom (33\%).

\section{Procedure}

Approval for the study was granted by an accredited Human Research Ethics Committee prior to data collection. Participants were recruited via three methods: (i) an online research participation pool, where students completing health science degrees sign up to participate in studies in return for course credit; (ii) posters placed around the university campus inviting participants to take part in the study; and (iii) announcements about the study, including the information sheet and survey link, distributed by unit co-ordinators to students enrolled within their units. The students who chose to participate in the study completed a multi-section survey online via Qualtrics (Qualtrics LLC, Utah, USA). All participants provided informed consent to take part in the study, via a check box at the beginning of the survey.

\section{Measures}

Adversity exposure. Participants' exposure to adversity across their lifetime was assessed using an adapted version of Seery et al.'s (2010) cumulative lifetime adversity measure. The adapted measure consisted of 15 negative events that captured the following six broad categories: own illness or injury, loved ones illness or injury, violence, bereavement, social/environmental stress, and relationship stress. An additional two categories were included within our adapted version to capture common experienced adversities: threat or harassment, and others' death or injury. Respondents indicated whether or not they had ever experienced the adversity $(0=$ no, $1=$ yes $)$ and, if so, how many times. For the purposes of this study a single dichotomous (yes or no) variable was created to represent each of the eight 
categories of adversity. For example, if participants indicated that they had experienced a 'major illness' but not a 'life threatening accident' (or vice versa), they would be scored as yes (1) to the adversity category own illness or injury. In cases where participants experienced both of these adversities, they were also coded as yes (1) to the adversity category own illness or injury. The combining of conceptually similar items to create a single binary category has been used in previous studies (e.g. Holt et al., 2017; Young-Wolff et al., $2013)^{2}$.

Resilience resources. Informed by findings from a recent conceptual and methodological review of resilience measures (Pangallo, Zibarras, Lewis, \& Flaxman, 2015), we assessed four broad resilience resources encapsulated by the concept of psychological capital, namely hope, efficacy, resilience, and optimism (Luthans, Youssef, \& Avolio, 2007). For each of the four scales items were measured on a 7-point scale anchored by 1 strongly disagree and 7 strongly agree.

Bounce back ability (Smith et al., 2008). The Brief Resilience Scale (BRS) is a measure of one's perceived ability to bounce back or recover from stress. The scale is comprised of six items, three of which are positively worded (e.g., "I tend to bounce back quickly after hard times") and three are negatively worded (e.g., "It is hard for me to snap back when something bad happens"). Scores on the BRS have demonstrated good levels of internal consistency $(\alpha=.81-.91)$ and test-retest reliability (1 month $r=.69$ and 3 months $r$ $=.62$ ) evidence in past work (Smith et al., 2008). Internal reliability evidence in the current sample was excellent $(\alpha=.91)$.

\footnotetext{
${ }^{2}$ One reviewer asked why we used a binary score (yes/no) to operationalize adversity exposure rather than a continuous or summative score to indicate the number of times participants had experienced each adverse event category. As explained in the supplementary material, this decision was largely statistical in nature rather than substantively informed (e.g., model fit statistics were unclear about the optimal number of classes, classes contained less than $5 \%$ of the total sample).
} 
Adult hope scale (Snyder et al., 1991). The Adult Hope Scale (AHS) is a measure of an individual's cognitive and motivation towards personally valued objectives. The scale is comprised of 12 items consisting of two factors, each of which is measured by four items; the four filler items were omitted in this study to minimise participant burden. The pathway items measure one's perception of their ability to overcome goal-related barriers to their goals (e.g., “There are lots of ways round any problem"), whereas the agency items reflect people's motivation and goal-directed energy to use pathways to reach their goal (e.g., "My past experiences have prepared me well for my future"). Scores on the AHS have demonstrated good reliability ( $\alpha=.79$; Feldman \& Kubota, 2015) and test-retest reliability evidence (3 weeks, $r=.85$ up to 10 weeks, $r=.82$; Snyder et al., 1991). Internal reliability evidence in the current sample was sound $(\alpha=.86)$.

General self-efficacy scale (Chen, Gully, \& Eden, 2001). The General Self-Efficacy Scale (GSE) is an 8-item measure of one's belief in their capabilities to perform the courses of action required to meet situational demands (e.g., "When facing difficult tasks, I am certain that I will accomplish them"). Scores on the GSE have demonstrated good internal consistency ( $\alpha=.82$; Chen, Li, \& Leung, 2016) and test-retest reliability evidence ( $r=.62$ to .86; Chen et al., 2001). Internal reliability evidence in the current sample was excellent ( $\alpha=$ $.92)$.

Life orientation test - revised (Scheier, Carver, \& Bridges, 1994). The Life Orientation Test-Revised (LOT-R) is a 10-item measure of an individual's perceived optimism (e.g., "I'm always optimistic about my future") and pessimism (e.g., "I rarely count on good things happening to me"). The two dimensions are measured with three items; the four filler items were omitted in the current study to minimise participant burden. Scores on the LOT-R have demonstrated good levels of internal consistency $(\alpha=.85$; Feldman $\&$ Kubota, 2015; $\alpha=.85 ;$ Huffman et al., 2016) and test-retest reliability evidence ( $\mathrm{r}=.73$; 
Atienza, Stephens, \& Townsend, 2004). Internal reliability evidence in the current sample was sound $(\alpha=.81)$.

\section{Data Analysis}

Latent class analyses (LCA) were conducted to identify subgroups or clusters of individuals based on their breadth (categorical indicator) of lifetime adversity exposure; that is, the total number of unique adversity experiences. These analyses are useful in reducing indicator variables into latent subgroups (Oberski, 2016). In the present study, we utilised the automatic 3-step method within Mplus (Muthén \& Muthén, 2017) to model auxiliary variables (e.g., covariates and distal outcomes). First, the 3-step method determines the number of latent classes based on the indicator variables, which in our case included eight broad categories of unique adverse events. Second, the most likely class membership for participants is determined based upon the posterior distribution obtained in step one. Finally, this classification scheme is related to covariates and distal outcomes. The 3-step method was chosen because it takes into account error in classification when estimating associations with other variables (Gabriel, Daniels, Diefendorff, \& Greguras, 2015), and class identification is uninfluenced by covariates or outcomes variables (Asparouhov \& Muthén, 2013). We initially fitted a 2-class model, then increased the number of classes by one, comparing the model fit statistics to ascertain if the increase in classes produced groups that were substantively meaningful and had a good fit statistically. A high number of initial stage random starts (1000) were utilised to avoid local solutions (i.e., a false maximum likelihood), which is a common problem with LCA models (Holt et al., 2017). All analyses were run using Mplus 8 (Muthén \& Muthén, 2017).

Different sources of information should be considered when assessing the optimum number of latent classes, including the substantive meaningfulness and the level of statistical fit of the possible solutions (Gillet, Morin, Cougot, \& Gagné, 2017; Marsh, Lüdtke, 
Trautwein, \& Morin, 2009). Multiple statistical indicators can be used to aid decision making (McLachlan \& Peel, 2000) and include: (a) Akaike's Information Criteria (AIC), (b) Consistent AIC (CAIC), (c) Bayesian Information Criteria (BIC), (d) sample size Adjusted Bayesian Information Criteria (ABIC), (e) Lo-Mendell-Rubin Likelihood RatioTest (LMR), (f) adjusted Lo-Mendell-Rubin Likelihood RatioTest (aLMR), and (g) Bootstrap Likelihood Ratio Test (BLRT). For the four information criteria (AIC, CAIC, BIC, and ABIC), a lower value indicates better model fit. The two likelihood ratio tests (aLMR and BLRT) are accompanied by a $p$ value for a comparison of model fit with a model with one less class, where a non-significant $p$ value indicates the model with one less profile should be retained (Morin \& Wang, 2016). Finally, entropy is an indicator of model precision with regard to classifying individuals into their most likely classes. Scores range from $0-1$ with a higher value representing greater accuracy (Diallo, Morin, \& Lu, 2016).

Simulation work has found four statistical indicators (CAIC, BIC, ABIC, and BLRT) to be most informative in identifying the correct number of classes (Nyland, Asparouhov, \& Muthén, 2007; Peugh \& Fan, 2013; Tofighi \& Enders, 2008). Conversely, the AIC, LMR and aLMR are suboptimal for informing decisions regarding the number of classes because they tend to support the extraction of the incorrect number of classes (Diallo et al., 2016; Nyland et al., 2007; Peugh \& Fan, 2013). All model fit indicators are reported here for clarity, though only the CAIC, BIC, ABIC, and BLRT were used to decide upon the optimal number of classes. Simulation work (Diallo et al., 2016) suggests that the ABIC and BLRT are preferred when entropy is lower (closer to .50), and the BIC and CAIC preferred when entropy levels are higher (closer to .90). Sample size is another important consideration for selecting the final model, because with a sufficiently large sample size the observed indicators may carry on suggesting the addition of more classes without reaching a minimum (Morin \& Wang, 2016). In such cases, the information criteria can be presented in elbow plots to show the 
gains offered by additional classes; the point at which the line flattens shows the optimum number of classes (Wang, Morin, Ryan, \& Liu, 2016).

Once the optimal solution had been identified, the covariates and outcomes were examined. For the covariates of age and sex, we used the R3STEP command (Asparouhov \& Muthén, 2013). To explore the outcomes as auxiliary variables we utilised the automatic BCH approach (Bakk \& Vermont, 2016). The BCH approach was chosen because it accounts for classification error and unequal variance across classes (Asparouhov \& Muthén, 2014). Means for outcomes were computed for each class and compared. The analyses of the covariates (R3STEP) and outcomes (BCH) were conducted separately, as these two methods cannot be run simultaneously in Mplus (Asparouhov \& Muthén, 2014).

\section{Results}

\section{Descriptive Statistics}

The proportions of the sample who had experienced a lifetime adversity category as well as descriptive statistics of the psychosocial factors by sex are detailed in Table 1. Sex differences were examined using chi-squared and $t$ tests. Adversities related to 'loved one's illness/injury' (49.7\%) and 'bereavement' (48.5\%) were the most commonly reported. Males reported significantly higher proportions of being threatened/harassed than females $(p=$ $.007)$, with no other significant differences observed between groups for adversities $(p=.102$ - .857). In terms of psychosocial factors, males reported significantly higher levels of perceived bounce back resilience than females $(p=.000)$.

\section{Class Identification}

Model fit statistics are detailed in Table 2. The CAIC, ABIC, and BLRT supported the superiority of the 3-class solution, whereas the BIC reached its minimum value at the 2class solution. As the entropy value was high, we preferred the CAIC and BIC values over the ABIC and BLRT. An examination of the elbow plot (see Figure 1) shows that with the 
exception of BIC, the lowest values were at the 3-class solution and the slopes began to increase with the addition of classes. These data suggest a preference for the 2-class and 3class solutions; we accepted the 3-class solution as the most viable because of the higher entropy value. Substantively, although the 2-class solution produced distinct classes in line with the study hypotheses, the addition of the third class clearly identified members who had experienced a different profile of adversities than the other classes. Notably, the 4-class solution produced a class consisting of only 12 members (3.4\%), which evidenced a similar pattern to the third class.

The estimated probabilities of the 3-class model are depicted in Figure 2. These plots display the probability that an individual within a latent class has experienced one of the lifetime adversity categories, and therefore how different latent classes are from each other across the lifetime adversity categories. The first class along the bottom of the plot, denoted by the dashed line, is characterised by relatively low probabilities $(<.33)$ of having experienced each of the lifetime adversity categories. This class was labelled Low Polyadversity and accounted for $41.1 \%$ of the sample. The second class, identified by the dotted line, had a low probability $(<.33)$ of experiencing all but two categories, where individuals reported moderate to high probabilities of experiencing bereavement (.60) and a loved one's illness/injury (1). This class contained $17.8 \%$ of the sample and was called Vicarious Adversity. The final class, denoted by the solid line, constituted the remaining $41.1 \%$ of the sample. This class was characterised by moderate to high probability of experiencing all categories, with the exception of relationship stress (.27); as such, we labelled this class as High Polyadversity.

\section{Covariates}

Sex and age differences were observed across the three classes. With regards to sex, females were more likely than males to be in the High Polyadversity class than the Vicarious 
Adversity $(-.95, \mathrm{SE}=.47, \mathrm{p}=.04)$ and Low Polyadversity classes $(-.63, \mathrm{SE}=.31, \mathrm{p}=.04)$. With regard to age, participants in the High Polyadversity class were older than individuals in both the Vicarious Adversity (-.21, SE = .08, $\mathrm{p}=.01)$ and Low Polyadversity $(-.09, \mathrm{SE}=.03$, $\mathrm{p}=.01)$ classes.

\section{Outcomes}

An examination of differences across classes in terms of psychosocial factors (see Table 3) shows a single statistically significant difference, with those students in the Vicarious Adversity class reporting lower levels of optimism than individuals in the Low Polyadversity class. The standardised outcome scores across the three classes are depicted in Figure 3.

\section{Study 2}

The results of the first study provided initial support for our expectations regarding classes of individuals who experienced low or high amounts of adversities (H1 and H2), or one specific type of adversity (H3). However, there were minimal differences between these classes in terms of self-reported resilience resources (H4). In this study, we replicated the aforementioned methodological approach with a larger sample and broader representation of the community than university students, particularly with regard to lifetime adversity exposure.

\section{Methods}

\section{Participants}

A sample of 1506 participants (51.8\% male) aged between $18-90$ years (mean \pm SD; $52.77 \pm 17.01)$ were recruited through the On-line Research Unit (ORU), Australia's largest on-line research panel. Simulation work suggests that a sample of this size should provide $80 \%$ power to detect small effects $(\sim w=.15)$ for a three or four class solution (Dziak, Lanza, \& Tan, 2014). 


\section{Procedure}

Approval for the study was granted by an accredited Human Research Ethics Committee prior to data collection. Participants were recruited using an online data collection agency (http://theoru.com). From a population of approximately 400,000 participants, the data collection agency distributed our survey via e-mail to a random sub-sample representative of the general population in terms of age, gender and geographical location. Those participants who opted to participate in the study completed the survey online via Qualtrics (Qualtrics LLC, Utah, USA). The survey included questions regarding basic demographic information, the occurrence of past adversities and individual level resilience resources. Participants also received a five dollar shopping voucher as compensation for their time completing the survey.

\section{Measures}

Adversity exposure. Similarly to Study 1, participants' exposure to adversity was assessed using an adapted version of Seery et al.'s (2010) measure. The measure differed slightly from the first study, in that 21 , as opposed to 15 , items were selected from the original measure (see the online supplementary material). The items again reflected the 8 broad categories of: own illness or injury, loved ones illness or injury, violence, bereavement, social/environmental stress, relationship stress, threat or harassment, and others death or injury. Participants indicated for each item whether they had experienced the adversity $(0=$ no, $1=$ yes). A composite score was created for each category of adversity to indicate whether the category had been experienced or not.

\section{Resilience resources}

The measures for the individual level resources again captured the four broad resilience resources encapsulated by the concept of psychological capital, namely hope, efficacy, resilience, and optimism (Luthans et al., 2007). With the exception of self-efficacy, 
the measures were identical to tools used in Study 1. Test scores in this study demonstrated good reliability evidence; BRS $(\alpha=.86)$, LOT-R $(\alpha=.81)$, and hope $(\alpha=.90)$.

Self-efficacy. An adapted measure based upon Bell and Kozlowski's (2002) tool was utilised to assess participant's self-efficacy in relation to lifetime adversity. The measure consisted of four items (e.g., "I am convinced that I can handle the demands in my life") that were assessed on a 7-point scale anchored by 1 strongly disagree and 7 strongly agree.

Scores on the scale have demonstrated good levels of internal consistency evidence $(\alpha=.82)$ in past research (Lindberg, Wincent, \& Örtqvist, 2013). Internal reliability evidence was excellent in the present study $(\alpha=.95)$.

\section{Data Analysis}

We used the same analyses as reported in Study 1.

\section{Results}

\section{Descriptive Statistics}

The proportions of the sample who experienced each lifetime adversity category and differences in psychosocial factors means are presented in Table 1. Bereavement was the most commonly reported adversity (85.9\%) followed by loved one's illness/injury (55.9\%). Males were more likely to have experienced illness/injury $(p=.019)$ and other death/injury ( $p$ $=.000)$, and less likely to have experienced loved one's illness/injury $(p=.000)$ and social/environmental stress $(p=.010)$ than females. Sex differences were also observed in outcome variables, with males reporting higher levels of bounce-back resilience $(p<.001)$, hope $(p=.000)$ and self-efficacy $(p=.000)$.

\section{Class Identification}

Model fit statistics of all models tested are detailed in Table 2. The CAIC, BIC, and ABIC all suggested a 3-class solution, whereas the BLRT supported additional classes until the 6-class solution. The entropy level was generally high, which would suggest a preference 
for the CAIC and BIC over the ABIC and BLRT. An examination of the elbow plot shows a flattening of the slope at the 3-class model (see Figure 4). In light of these results, the 3-class solution was retained for further examination.

Three distinct classes can be seen in the estimated probability plot for an individual having experienced the examined lifetime adversity categories (see Figure 5). The first class can be seen along the bottom of the plot, denoted by the dashed line; participants in this class had the lowest probabilities of experiencing all lifetime adversity categories, with the exception of bereavement (.42). This class accounted for $16.8 \%$ of the sample and was labelled Low Polyadversity. The second class, denoted by the solid line, accounted for $20.5 \%$ of the sample. This class had the highest probabilities of experiencing all lifetime adversity categories $(.66-1)$, with the exception of threat/harassment (.48) and other death/injury (.59). This class was labelled High Polyadversity. The final class, identified by the dotted line, can be seen to have category probabilities that fall between those of the other two classes. They experienced low probabilities in three categories (threat/harassment, violence, and other death/injury), moderate probabilities in four (illness/injury, loved one's illness/injury, social/environmental stress, and relationship stress), and a high probability of bereavement (.93). This class was labelled Moderate Polyadversity, and contained $62.7 \%$ of the sample.

\section{Covariates}

A number of demographic differences were found between classes in terms of the observed covariates. Males were more likely to be in the Low Polyadversity class than the Moderate Polyadversity class $(.55, \mathrm{SE}=.24, p=.02)$. Individuals within the Low Polyadversity class were younger than those participants in both the Moderate Polyadversity $(.08, \mathrm{SE}=.01, p<.001)$ and High Polyadversity $(.06, \mathrm{SE}=.01, p<.001)$ classes. Finally, 
individuals in the High Polyadversity class were significantly younger than those people in the Moderate Polyadversity $(-.02, \mathrm{SE}=.01, p<.01)$ class.

\section{Outcomes}

The results for the psychosocial variables show a number of differences between classes (see Table 4); standardised scores for each psychosocial variable across the three classes are depicted in Figure 6. Individuals in the Low Polyadversity class reported lower levels of resilience and optimism than people in the Moderate Polyadversity Class. The Low Polyadversity class also reported higher levels of all outcome variables than individuals in the High Polyadversity class. Participants in the High Polyadversity class reported lower levels of all psychosocial variables than individuals in the Moderate Polyadversity class.

\section{Discussion}

The current study utilised a person-centred approach to examine subpopulations of adversity exposure in two samples. We further examined differences between adversity class memberships and individual-level resilience resources. H1 was supported, such that we observed in both samples a class characterised by a relatively high likelihood of experiencing most or all of the assessed adversities (High Polyadversity). H2 was also supported with a class identified in both samples characterised by a lower likelihood of experiencing most or all of the assessed adversities (Low Polyadversity). H3 was partially supported, such that in Study 1 we identified a class characterised by a high likelihood of experiencing a specific trauma (Vicarious Adversity), yet in Study 2 the third class was characterised by moderate experiences of adversities (Moderate Polyadversity). H4 was also partially supported, such that in Study 2 the moderate polyadversity class was associated with higher levels of all resources than the high adversity class and higher levels in two of the four resources (optimism and resilience) than the low adversity class. However, these differences in reported 
individual-level resilience resources were largely absent from the student sample in Study 1, with the exception of optimism.

Although past work has examined how certain adversities can affect individual-level resilience resources (e.g., Kivimäki et al., 2005), there has been little research on how the experience of multiple adversities might contribute to an individual's resilience capacity. The question is of interest for both substantive (e.g., qualitative differences in adversity experiences) and practical (e.g., interventions, and health care) reasons. The latent classes we observed within the present study were largely in line with our hypotheses, such that we revealed three distinct classes that best represented polyadversity profiles. The review informing our hypotheses found seven of the nine reviewed studies reported a 'high-trauma class' and all nine reported a 'low-trauma class' (Contractor et al., 2018). Classes with a similar interpretation were observed in the current study across the student and community samples. Although the two samples revealed both high and low polyadversity classes with similar numbers within each, the proportional distribution of classes differed between studies. Specifically, in the student sample the high and low polyadversity classes were comprised of the same proportion of participants $(41.3 \%)$, whereas in the community sample classes the proportion of members was roughly half $($ low $=16.8 \%$; high $=20.5 \%)$. Contractor et al. (2018) found in their review that the classes characterised by high levels of adversity were the smallest. It should be noted that within the review, the studies mainly focused on interpersonal adversities ( 8 of 9). It has also been found that when categorising participants by total number of adversities experienced (e.g., zero, low, high), the high category contained more participants than the zero- and low-adversity categories (Seery et al., 2010). A key methodological difference with past work is that we considered a broad array of lifetime adversities, many of which were absent from previous research on adversity exposure. This extension was informed by recommendations for researchers to take into consideration 
adversities beyond the narrow focus of interpersonal adversities (Contractor et al., 2018). This widening of scope may account for the observed differences in the proportions of those who reported higher levels of polyadversity.

Differences between latent classes of adversity exposure in terms of individual-level resilience resources were mixed. Briefly, the findings of Study 2 were consistent with our expectations, such that members of the moderate polyadversity class reported the highest levels of all resources across the three classes. These differences were statistically significant for all four resilience resources when comparing the moderate class with the high polyadversity class, yet only for bounce back resilience and optimism when comparing against the low polyadversity class. Conceptually, the findings are consistent with the view that a moderate amount of adversity is optimal, over high and no adversity, to allow for toughening or the opportunity for individual's to develop and/or refine resilience resources (Dienstbier, 1992; Höltge et al., 2018). Speculatively, this opportunity may occur via systematic self-reflection strengthening resilience (Crane et al., 2018). Empirically, the findings are consistent with previous work which has identified a U-shaped association between lifetime adversity and indicators of positive functioning or an inverted U-shaped association with markers of negative functioning (e.g., Höltge et al., 2018; Kondrak \& Seery, 2015; Seery et al., 2010; Seery et al., 2013; Seery, Leo et al., 2010). These series of studies consistently found that exposure to some adversity was associated with adaptive (higher/lower) levels of a variety of psychological well-being outcomes (e.g., life satisfaction, global distress, post-traumatic stress) than a history of no/low or high levels of adversity. Furthermore, exposure to some adversity was associated with being less negatively affected by recent adversity, consistent with the development of resilience (Seery et al., 2010; Seery, Leo et al., 2010). 
Our findings add another layer to previous work by suggesting that exposure to a moderate amount of adversity builds resilience through providing the opportunity to develop these individual-level resources. In turn, research has supported the adaptive nature of these resilience resources, such that people who report higher levels fare better psychologically and physiologically in terms of perceived stress (Lines et al., 2018; Riolli, Savicki, \& Richards, 2012), well-being (Avey, Reichard, Luthans, \& Mhatre, 2011), body mass index, and blood cholesterol concentration (Luthans, Youssef, Sweetman, \& Harms, 2013). Interestingly, members of the high polyadversity class also had significantly lower levels of all resources that those in the low polyadversity class. This suggests that exposure to a fewer adversities many enable an individual to develop these adaptive resources to a lesser extent than a moderate amount of adversity, though exposure to high amounts is highly detrimental to the perceived availability of resources. In a recent review, members of high polytraumatisation classes demonstrated the worst health outcomes when compared to those in other classes (e.g., greater likelihood of posttraumatic stress disorder, anxiety, depression, alcohol and drug use and self-harm; Contractor et al., 2018). These deleterious effects may be a result of the sensitising role of stressors or adversities, in that exposure to an adversity may sensitise an individual to a lower level adversity in the future (Stroud, Davila, Hammen, \& VrshekSchallhorn, 2011). This sensitisation may lead to maladaptive responses being triggered, undermining resilience (e.g., rumination, self-doubt) in response to lesser adverse events which in turn develops into one's natural response to an adversity (Crane et al., 2018). In light of the frequently observed beneficial effects of a moderate amount of exposure to adversity, research exploring this sensitisation hypothesis should also look at both positive and negative effects.

Differences in individual-level resilience resources between the three classes among the student sample were mixed. Of all the comparisons, only one difference was statistically 
significant, whereby individuals in the vicarious adversity class reported lower levels of optimism than people in the low polyadversity class. One key difference between the two classes is in the category of loved one's illness/injury, with all members of the vicarious class and none in the low polyadversity having experienced this type of adversity. Kivimäki et al. (2005) examined changes in optimism and pessimism following death or severe illness of a loved one, and found that pessimism rose by $10 \%$ following the onset of an illness of a loved one, though fell by $4 \%$ with the absence of such an adversity. This past work provides a useful backdrop upon which to interpret the finding in the current study, as we used a cumulative score for optimism based on the support for the summative unidimensional approach within the literature (Carver \& Scheier, 2018). This observation can be seen as important as higher levels of optimism are associated with protective benefits following both severe and mild adverse events (e.g., Chang \& Sanna, 2003; Kivimäki et al., 2005). Therefore, it may be beneficial in future research to examine whether interventions aiming to increase optimism (e.g., Blackwell et al., 2013) help individuals via these adaptive benefits following bereavement, or illness/injury of a loved one.

The main difference between the two samples in this study was the nature of the third class. Both classes were characterised by a relatively high $(\geq 0.6)$ likelihood of experiencing the adversities of bereavement and loved one's illness/injury. However, the community sample in Study 2 had a moderate probability of having experienced an illness/injury, social/environmental stressor, and relationship stressor alongside the two vicarious adversities, whereas the student sample evidenced a low probability of all other adversities. Within both samples the shapes of the probability plots are similar for this third class, though they differed on the proportion of members with only $17.3 \%$ in the first sample, compared to $62.7 \%$ in the second sample. Interestingly, in Contractor et al.'s (2018) review none of the papers reported a moderate class, though all reported at least one specific trauma class with 
proportions ranging from $3.6 \%-62.6 \%($ mean $=22.1 \%)$. The nature of this third class makes comparison between the two classes complex as they are substantively different; that is, one is characterised by endorsement of specific adversities whereas the other is characterised by an overall moderate degree of exposure. The observed differences may have emerged due to the nature of the samples within the two studies, with the first consisting of students $\left(\mathrm{M}_{\mathrm{age}}=\right.$ 22.09) and the second an older community sample $\left(\mathrm{M}_{\mathrm{age}}=52.77\right)$. One might think that with a higher age the older participants have had more time to experience adversities than their younger counterparts, though the adversities faced by younger people may have occurred in more recent memory and are thus more easily recalled (Seery \& Quinton, 2016). Indeed, when age has been controlled for as a covariate in past research, it has no effect on outcomes across student and community samples (e.g., Seery et al., 2010; Seery et al., 2013; Seery, Leo et al., 2010). A second possible reason for the findings is that within younger samples of individuals, the categories of bereavement and loved one's illness/injury may be more pertinent. In their study of 68,894 individuals, Benjet and colleagues (2016) found that younger (18-34 years) participants were more likely than older (65+ years) people to report having experienced, amongst others, unexpected death of a loved one. Finally, adversities that are important for this age group may have been missing from the checklist used in the current study and past work, or were not entirely obvious to participants (e.g., peer bullying).

\section{Strengths and Limitations}

Key strengths of this study include the person-centred approach to examining adversity exposure, differential effects of adversity experiences and resilience resources, and tests of the study hypotheses in two independent samples. Nevertheless, the current study is not without limitation. Our focus on four individual-level resilience resources may be seen as narrow and therefore requires expansion within future research (e.g., social resources). Furthermore, the assessment of adversity exposure was characterised by a dichotomous 
yes/no response, and therefore excluded an indication as to when the adversity occurred in their developmental pathway. Future research may look to consider the breadth (i.e., number of different adversities) and the depth (i.e., the frequency, intensity, and duration) of adversities experienced. Despite our efforts to examine the robustness of the findings across two samples, the extent to which the nature of the tripartite typology of lifetime adversity exposure generalises remain uncertain, particularly with respect to the third class where we observed important differences between the university study and community samples and the minimal demographic information collected from our two samples. The cross-sectional nature of the study means that we cannot speak confidently to causality and can only infer such relations from theory (e.g., toughness). Finally, the data was collected via self-report and as such may be affected by self-report biases.

\section{Conclusion}

The current study provides initial evidence of how exposure to lifetime adversities group together in two samples, and how class membership is associated with individual-level resilience resources. Across two independent samples - one a group of university students and the other a largely representative community sample - we revealed support for a tripartite representation of individual's experiences of multiple lifetime adversities. A low polyadversity and high polyadversity profile were evident among both samples, with the third class characterised by either two core vicarious adversities (students) or moderate levels across several adversities (community sample). Mixed support was found for our hypotheses regarding differences in individual-level resilience resources between classes; the adaptive nature of a moderate amount of adversity experiences was supported in the community sample but not the students. Our findings regarding the adaptive nature of adversity in the community sample are consistent with literature in other areas. For example, within the context of competitive sport, adversity has been found to distinguish between the super-elite 
(won at least one gold plus another gold or silver at a major championship) and elite (received athlete personal awards but not medalled at a major championship) athletes, particularly when coupled with a positive sport-related event (Hardy et al., 2017). Broadly, our findings underscore the importance of person-centred approaches to advancing our understanding on the nature of adversity experiences, their interplay, and their associations with resilience resources. 


\section{References}

American Psychiatric Association. (2013). Diagnostic and statistical manual of mental disorders (5th ed.). Washington, DC: Author.

Armour, C., \& Sleath, E. (2014). Assessing the co-occurrence of intimate partner violence domains across the life-course: Relating typologies to mental health. European Journal of Psychotraumatology, 5(1), 24620. Doi: 10.3402/ejpt.v5.24620

Asparouhov, T. \& Muthen, B. (2013). Auxiliary variables in mixture modeling: Three-step approaches using Mplus. Structural Equation Modeling: A Multidisciplinary Journal, 21, 329-341. Doi: 10.1080/10705511.2014.915181

Asparouhov, T., \& Muthén, B. (2014). Auxiliary variables in mixture modeling: Using the $\mathrm{BCH}$ method in Mplus to estimate a distal outcome model and an arbitrary second model. Mplus Web Notes, 21, 1-22. Retrieved from:

https://www.statmodel.com/examples/webnotes/webnote21.pdf

Atienza, A. A., Stephens, M. A. P., \& Townsend, A. L. (2004). Role stressors as predictors of changes in womens' optimistic expectations. Personality and Individual Differences, 37, 471-484. Doi: 10.1016/j.paid.2003.09.016

Avey, J. B., Reichard, R. J., Luthans, F., \& Mhatre, K. H. (2011). Meta-analysis of the impact of positive psychological capital on employee attitudes, behaviors, and performance. Human Resource Development Quarterly, 22, 127-152.

Bakk, Z., \& Vermunt, J. K. (2016). Robustness of stepwise latent class modeling with continuous distal outcomes. Structural Equation Modeling: A Multidisciplinary Journal, 23, 20-31. Doi: 10.1080/10705511.2014.955104

Bandura, A. (1997). Self-Efficacy: The exercise of control. New York: Freeman. 
Basoglu, M., Mineka, S., Paker, M., Aker, T., Livanou, M., \& Gok, S. (1997). Psychological preparedness for trauma as a protective factor in survivors of torture. Psychological Medicine, 27, 1421-1433. Doi: 10.1017/S0033291797005679

Bell, B. S., \& Kozlowski, W. J. (2002). Goal orientation and ability: Interactive effects on self-efficacy, performance, and knowledge. Journal of Applied Psychology, 87, 497505. Doi: 10.1037/0021-9010.87.3.497

Benjet, C., Bromet, E., Karam, E. G., Kessler, R. C., McLaughlin, K. A., Ruscio, A. M., ... \& Alonso, J. (2016). The epidemiology of traumatic event exposure worldwide: results from the World Mental Health Survey Consortium. Psychological Medicine, 46, $327-$ 343. Doi: $10.1017 / \mathrm{S} 0033291715001981$

Berlin, K. S., Williams, N. A., \& Parra, G. R. (2014). An introduction to latent variable mixture modeling (part 1): Overview and cross-sectional latent class and latent profile analyses. Journal of Pediatric Psychology, 39, 174-187. Doi:10.1093/jpepsy/jst084

Blackwell, S. E., Rius-Ottenheim, N., Schulte-van Maaren, Y. W., Carlier, I. V., Middelkoop, V. D., Zitman, F. G., ... \& Giltay, E. J. (2013). Optimism and mental imagery: A possible cognitive marker to promote well-being? Psychiatry Research, 206, 56-61. Doi: 10.106/j.psychres.2012.09.047

Bonanno, G. A., Romero, S. A., \& Klein, S. I. (2015). The temporal elements of psychological resilience: An integrative framework for the study of individuals, families, and communities. Psychological Inquiry, 26, 139-169. Doi: 10.1080/1047840X.2015.992677

Bonanno, G. A., Westphal, M., \& Mancini, A. D. (2011). Resilience to loss and potential trauma. Annual Review of Clinical Psychology, 7, 511-535. Doi: 10.1146/annurevclinpsy-032210-104526 
Briere, J., Agee, E., \& Dietrich, A. (2016). Cumulative trauma and current posttraumatic stress disorder status in general population and inmate samples. Psychological Trauma: Theory, Research, Practice, and Policy, 8, 439-446. Doi:

$10.1037 / \operatorname{tra} 0000107$

Burns, C. R., Lagdon, S., Boyda, D., \& Armour, C. (2016). Interpersonal polyvictimization and mental health in males. Journal of Anxiety Disorders, 40, 75-82. Doi: 10.1016/j.janxdis.2016.04.002

Carver, C. S., \& Scheier, M. F. (2018). Generalized optimism. In G. Oettingen, A. T. Sevincer, P. M. Gollwitzer (Eds.), The psychology of thinking about the future (pp. 214-230). London, UK: The Guildford Press.

Cavanaugh, C. E., Martins, S. S., Petras, H., \& Campbell, J. C. (2013). Mental disorders associated with subpopulations of women affected by violence and abuse. Journal of Traumatic Stress, 26, 459-466. Doi: 10.1002/jts.21821

Chang, E. C., \& Sanna, L. J. (2003). Experience of life hassles and psychological adjustment among adolescents: does it make a difference if one is optimistic or pessimistic? Personality and Individual Differences, 34(5), 867-879. Doi: 10.1016/S01918869(02)00077-6

Chen, G., Gully, S. M., \& Eden, D. (2001). Validation of a new general self-efficacy scale. Organizational Research Methods, 4, 62-83. Doi: 10.1177/109442810141004

Chen, T., Li, F., \& Leung, K. (2016). When does supervisor support encourage innovative behavior? Opposite moderating effects of general self-efficacy and internal locus of control. Personnel Psychology, 69, 123-158. Doi: 10.1111/peps.12104

Chmitorz, A., Kunzler, A., Helmreich, I., Tüscher, O., Kalisch, R., Kubiak, T., Wessa, W., \& Lieb, K (2018). Intervention studies to foster resilience - A systematic review and 
proposal for a resilience framework in future intervention studies. Clinical Psychology Review, 59, 78-100. Doi: 10.1016/j.cpr.2017.11.002

Contractor, A. A., Caldas, S., Fletcher, S., Shea, M. T., \& Armour, C. (2018). Empirically derived lifespan polytraumatization typologies: A systematic review. Journal of Clinical Psychology, 74, 1137-1159. Doi: 10.1002/jclp.22586

Crane, M. F., Searle, B. J., Kangas, M., \& Nwiran, Y. (2018). How resilience is strengthened by exposure to stressors: the systematic self-reflection model of resilience strengthening. Anxiety, Stress, \& Coping. Doi: 10.1080/10615806.2018.1506640

Diallo, T. M. O, Morin, A. J. S., \& Lu, H. (2016). The impact of total and partial inclusion or exclusion of active and inactive time invariant covariates in growth mixture models. Psychological Methods, 22, 166-190. Doi: 10.1037/met0000084

Dienstbier, R. A. (1989). Arousal and physiological toughness: Implications for mental and physical health. Psychological Review, 96, 84-100. Doi: 10.1037/0033-295X.96.1.84

Dienstbier, R. A. (1992). Mutual impacts of toughening on crises and losses. In L. Montada, S. H. Filipp, \& M. J. Lerner (Eds.), Life crises and experiences of loss in adulthood (pp. 367-384). Hillsdale, NJ: Erlbaum.

Dooley, L. N., Slavich, G. M., Moreno, P. I., \& Bower, J. E. (2017). Strength through adversity: Moderate lifetime stress exposure is associated with psychological resilience in breast cancer survivors. Stress and Health, 33, 549-557. Doi: 10.1002/smi.2739

Dziak, J. J., Lanza, S. T., \& Tan, X. (2014). Effect size, statistical power, and sample size requirements for the bootstrap likelihood ratio test in latent class analysis. Structural Equation Modeling, 21, 534-552. https://doi.org/10.1080/10705511.2014.919819 
Elliott, A. N., Alexander, A. A., Pierce, T. W., Aspelmeier, J. E., \& Richmond, J. M. (2009). Childhood victimization, poly-victimization, and adjustment to college in women. Child Maltreatment, 14, 330-343. Doi: 10.1177/1077559509332262

Feldman, D. B., \& Kubota, M. (2015). Hope, self-efficacy, optimism, and academic achievement: Distinguishing constructs and levels of specificity in predicting college grade-point average. Learning and Individual Differences, 37, 210-216. Doi: 10.1016/j.lindif.2014.11.022

Finkelhor, D., Ormrod, R. K., \& Turner, H. A. (2007). Polyvictimization and trauma in a national longitudinal cohort. Development and Psychopathology, 19, 149-166. Doi: $10.1017 / \mathrm{S} 0954579407070083$

Fletcher, D. (2018). Psychological resilience and adversarial growth in sport and performance. In Braddick, O. (Ed.), Oxford Research Encyclopaedia: Psychology. Oxford, UK: Oxford University Press.

Fletcher, D. and Sarkar, M. (2016). Mental fortitude training: An evidence-based approach to developing psychological resilience for sustained success. Journal of Sport Psychology in Action, 7, 135-157.

Gabriel, A. S., Daniels, M. A., Diefendorff, J. M., \& Greguras, G. J. (2015). Emotional labor actors: A latent profile analysis of emotional labor strategies. Journal of Applied Psychology, 100, 863-879. Doi: 10.1037/a0037408

Gillet, N., Morin, A. J., Cougot, B., \& Gagné, M. (2017). Workaholism profiles: Associations with determinants, correlates, and outcomes. Journal of Occupational and Organizational Psychology, 90, 559-586. Doi: 10.1111/joop.12185

Gucciardi, D. F., Crane, M., Ntoumanis, N., Parker, S. K., Thøgersen-Ntoumani, C., Ducker, K. J., ... \& Temby, P. (2018). The emergence of team resilience: A multilevel 
conceptual model of facilitating factors. Journal of Occupational and Organizational Psychology. Doi:10.1111/joop.12237

Gustafsson, P. E., Nilsson, D., \& Svedin, C. G. (2009). Polytraumatization and psychological symptoms in children and adolescents. European Child \& Adolescent Psychiatry, 18, 274-283. Doi: 10.1007/s00787-008-0728-2

Hardy, L., Barlow, M., Evans, L., Rees, T., Woodman, T., Warr, C. (2017). Great British medalists: psychosocial biographies of super-elite and elite athletes from Olympic sports. Progress in Brain Research, 232, 1-119. Doi: 10.1016/bs.pbr.2017.03.004

Holt, M. K., Felix, E., Grimm, R., Nylund-Gibson, K., Green, J. G., Poteat, V. P., \& Zhang, C. (2017). A latent class analysis of past victimization exposures as predictors of college mental health. Psychology of Violence, 7(4), 521-532. Doi:

$10.1037 /$ vio0000068

Höltge, J., Mc Gee, S. L., Maercker, A., \& Thoma, M. V. (2018). A salutogenic perspective on adverse experiences: The curvilinear relationship of adversity and well-being. European Journal of Health Psychology, 25, 53-69. Doi: 10.1027/2512$8442 / \mathrm{a} 000011$

Huffman, J. C., Beale, E. E., Celano, C. M., Beach, S. R., Belcher, A. M., Moore, S. V., ... \& Januzzi, J. L. (2016). Effects of optimism and gratitude on physical activity, biomarkers, and readmissions after an acute coronary syndrome. Circulation: Cardiovascular Quality and Outcomes, 9, 55-63. Doi:

10.1161/circoutcomes. 115.002184

Hughes, K., Bellis, M. A., Hardcastle, K. A., Sethi, D., Butchart, A., Mikton, C., ... \& Dunne, M. P. (2017). The effect of multiple adverse childhood experiences on health: a systematic review and meta-analysis. The Lancet Public Health, 2, e356-e366. Doi: $10.10 .16 /$ S2468-2667(17)30118-4 
Kivimäki, M., Vahtera, J., Elovainio, M., Helenius, H., Singh-Manoux, A., \& Pentti, J. (2005). Optimism and pessimism as predictors of change in health after death or onset of severe illness in family. Health Psychology, 24(4), 413-421. Doi: 10.1037/02786133.24 .4 .413

Kondrak, C. L., \& Seery, M. D. (2015). Can present perceptions of control outweigh our past? Control and cumulative lifetime adversity's association with positive responses to pain. Paper presented at Annual Meeting of the Midwestern Psychological Association, Chicago, USA.

Lanza, S. T., \& Cooper, B. R. (2016). Latent class analysis for developmental research. Child Development Perspectives, 10, 59-64. Doi: 10.1111/cdep.12163

Lindberg, E., Wincent, J., \& Örtqvist, D. (2013). Turning stressors into something productive: An empirical study revealing nonlinear influences of role stressors on self-efficacy. Journal of Applied Social Psychology, 43, 263-274. Doi: 10.1111/j.1559-1816.2012.00995.x

Lines, R. L. J., Ducker, K. J., Ntoumanis, N., Thøgersen-Ntoumani, C., Fletcher, D., McGarry, S., \& Gucciardi, D. (2018). Stress, physical activity, and resilience resources: Tests of direct and moderation effects in young adults. Sport, Exercise, and Performance Psychology. Doi: 10.1037/spy0000152

Luthans, F., Avey, J. B., Avolio, B. J., Norman, S. M. and Combs, G. M. (2006). Psychological capital development: Toward a micro-intervention. Journal of Organizational Behaviour, 27, 387-393. Doi: 10.1002/job.373

Luthans, F., Youssef, C. M., \& Avolio, B. J. (2007). Psychological capital: Developing the human competitive edge. New York, NY: Oxford University Press.

Luthans, F., Youssef, C. M., Sweetman, D. S., \& Harms, P. D. (2013). Meeting the leadership challenge of employee well-being through relationship PsyCap and health PsyCap. 
Journal of Leadership \& Organizational Studies, 20, 118-133. Doi:

$10.1177 / 1548051812465893$

Luthar, S. S., \& Cicchetti, D. (2000). The construct of resilience: Implications for interventions and social policies. Development and Psychopathology, 12, 857-885.

Marsh, H. W., Lüdtke, O., Trautwein, U., \& Morin, A. J. (2009). Classical latent profile analysis of academic self-concept dimensions: Synergy of person-and variablecentered approaches to theoretical models of self-concept. Structural Equation Modeling, 16, 191-225. Doi: 10.1080/10705510902751010

Masten, A. S. (2011). Resilience in children threatened by extreme adversity: Frameworks for research, practice, and translational synergy. Development and Psychopathology, 23, 493-506. doi:10.1017/S0954579411000198

McLachlan, G., \& Peel, D. (2000). Finite mixture models. New York, NY: Wiley.

Meichenbaum, D. (1976). A self-instructional approach to stress management: A proposal for stress inoculation training. In C. Spielberger \& I. Sarason (Eds.), Stress and anxiety in modern life. New York, NY: Winston.

Meichenbaum, D. (1977). Cognitive behavior modification: An integrative approach. New York, NY: Plenum Press.

Morin, A. J. S., \& Wang, J. C. K. (2016). A gentle introduction to mixture modeling using physical fitness performance data. In N. Ntoumanis, N. Myers (Eds.), An introduction to intermediate and advanced statistical analyses for sport and exercise scientists, (pp. 183-209). London, UK: Wiley.

Muthén, L. K., \& Muthén, B. O. (1998-2017). Mplus user's guide (8th ed.). Los Angeles, CA: Muthén \& Muthén. 
Nylund, K. L., Asparouhov, T., \& Muthén, B. (2007). Deciding on the number of classes in latent class analysis and growth mixture modeling: A Monte Carlo simulation study. Structural Equation Modeling, 14, 535-569. Doi: 10.1080/10705510701575396

Oberski, D. L. (2016). Mixture models: Latent profile and latent class analysis. In J. Robertson \& M. Kaptein (Eds.), Modern statistical methods for HCI (pp. 275-287). Switzerland: Springer International Publishing.

Pangallo, A., Zibarras, L., Lewis, R., \& Flaxman, P. (2015). Resilience through the lens of interactionism: A systematic review. Psychological Assessment, 27, 1-20. Doi: $10.1037 /$ pas0000024

Peugh, J., \& Fan, X. (2013). Modeling unobserved heterogeneity using latent profile analysis: A Monte Carlo simulation. Structural Equation Modeling, 20, 616-639. Doi: $10.1080 / 10705511.2013 .824780$

Rand, K. L., Martin, A. D., \& Shea, A. M. (2011). Hope, but not optimism, predicts academic performance of law students beyond previous academic achievement. Journal of Research in Personality, 45, 683-686. Doi:10.1016/j.jrp.2011.08.004

Riolli, L., Savicki, V., \& Richards, J. (2012). Psychological capital as a buffer to student stress. Psychology, 3, 1202-1207. Doi: 10.4236/psych.2012.312A178

Rutter, M. (1987). Psychosocial resilience and protective mechanisms. American Journal of Orthopsychiatry, 57, 316-331.

Scheier, M. F., Carver, C. S., \& Bridges, M. W. (1994). Distinguishing optimism from neuroticism (and trait anxiety, self-mastery, and self-esteem): a reevaluation of the Life Orientation Test. Journal of Personality and Social Psychology, 67, 1063-1078. Doi: 10.1037/0022-3514.67.6.1063 
Seery, M. D., Holman, E. A., \& Silver, R. C. (2010). Whatever does not kill us: Cumulative lifetime adversity, vulnerability, and resilience. Journal of Personality and Social Psychology, 99, 1025-1041. Doi: 10.1037/a0021344

Seery, M. D., Leo, R. J., Holman, E. A., \& Silver, R. C. (2010). Lifetime exposure to adversity predicts functional impairment and healthcare utilization among individuals with chronic back pain. Pain, 150, 507-515. Doi: 10.1016/j.pain.2010.06.007

Seery, M. D., Leo, R. J., Lupien, S. P., Kondrak, C. L., \& Almonte, J. L. (2013). An upside to adversity? Moderate cumulative lifetime adversity is associated with resilient responses in the face of controlled stressors. Psychological Science, 24, 1181-1189. Doi: $10.1177 / 0956797612469210$

Seery, M. D., \& Quinton, W. J. (2016). Understanding resilience: From negative life events to everyday stressors. Advances in Experimental Social Psychology, 54, 181-245. Doi: 10.1016/bs.aesp.2016.02.002

Smith, B. W., Dalen, J., Wiggins, K., Tooley, E., Christopher, P., \& Bernard, J. (2008). The brief resilience scale: Assessing the ability to bounce back. International Journal of Behavioral Medicine, 15, 194- 200. Doi: 10.1080/10705500802222972

Smith, B. W., Tooley, E. M., Christopher, P. J., \& Kay, V. S. (2010). Resilience as the ability to bounce back from stress: A neglected personal resource?. The Journal of Positive Psychology, 5, 166-176.

Snyder, C. R., Harris, C., Anderson, J. R., Holleran, S. A., Irving, L. M., Sigmon, S. T., ... \& Harney, P. (1991). The will and the ways: development and validation of an individual-differences measure of hope. Journal of Personality and Social Psychology, 60, 570-585. Doi: 10.1037/0022-3514.60.4.570 
Snyder, C. R., Shorey, H. S., Cheavens, J., Pulvers, K. M., Adams III, V. H., \& Wiklund, C. (2002). Hope and academic success in college. Journal of Educational Psychology, 94, 820-826. Doi:10.1037//002-0663.94.4.820

Stroud, C. B., Davila, J., Hammen, C., \& Vrshek-Schallhorn, S. (2011). Severe and nonsevere events in first onsets versus recurrences of depression: Evidence for stress sensitization. Journal of Abnormal Psychology, 120, 142-154. Doi: $10.1037 / \mathrm{a} 0021659$

Wang, J. C., Morin, A. J., Ryan, R. M., \& Liu, W. C. (2016). Students' motivational profiles in the physical education context. Journal of Sport and Exercise Psychology, 38(6), 612-630. Doi: 10.1123/jsep.2016-0153

Windle, G. (2011). What is resilience? A review and concept analysis. Reviews in Clinical Gerontology, 21, 152-169. doi: 10.1017/S0959259810000420

Young-Wolff, K. C., Hellmuth, J., Jaquier, V., Swan, S. C., Connell, C., \& Sullivan, T. P. (2013). Patterns of resource utilization and mental health symptoms among women exposed to multiple types of victimization: A latent class analysis. Journal of Interpersonal Violence, 28, 3059-3083. Doi: 10.1177/0886260513488692 
PROFILES OF ADVERSITY AND RESILIENCE RESOURCES

Table 1

Descriptive Statistics by Sex

\begin{tabular}{|c|c|c|c|c|}
\hline \multicolumn{5}{|c|}{ Study $1\left(N=324^{\#}\right)$} \\
\hline Variables & Total & Male & Female & $X^{2}$ \\
\hline \multicolumn{5}{|l|}{ LCA Indicators } \\
\hline Illness/Injury & $39.8 \%$ & $36.4 \%$ & $41.6 \%$ & .36 \\
\hline Threat/Harassment & $31.2 \%$ & $40.9 \%$ & $26.2 \%$ & $7.36^{* *}$ \\
\hline Violence & $31.2 \%$ & $31.8 \%$ & $30.8 \%$ & .30 \\
\hline Bereavement & $48.5 \%$ & $54.5 \%$ & $45.3 \%$ & 2.47 \\
\hline Loved Ones Illness/Injury & $49.7 \%$ & $51.8 \%$ & $48.6 \%$ & .30 \\
\hline Others Death/Injury & $35.2 \%$ & $40.9 \%$ & $32.2 \%$ & 2.39 \\
\hline Social/Environmental Stress & $29.6 \%$ & $31.8 \%$ & $28.5 \%$ & .38 \\
\hline Relationship Stress & $27.5 \%$ & $21.8 \%$ & $30.4 \%$ & 2.67 \\
\hline Outcomes & $\begin{array}{l}\text { Overall } M \\
\quad(S D)\end{array}$ & Male $M(S D)$ & Female $M(S D)$ & $\mathrm{T}$ \\
\hline BRS & $3.44(1.29)$ & $3.85(1.16)$ & $3.22(1.30)$ & $-4.29 * * *$ \\
\hline HOPE & $4.08(.97)$ & $4.04(.96)$ & $4.09(.97)$ & .47 \\
\hline LOT & $3.64(1.06)$ & $3.74(1.03)$ & $3.60(1.07)$ & -1.14 \\
\hline GSE & $4.15(.97)$ & $4.22(.98)$ & $4.11(.96)$ & -.96 \\
\hline \multicolumn{5}{|c|}{ Study $2(N=1506)$} \\
\hline Variables & Total & Male & Female & $X^{2}$ \\
\hline LCA Indicators (number of missing val & & & & \\
\hline Illness/Injury (133) & $46.1 \%$ & $48.9 \%$ & $42.5 \%$ & $5.48^{*}$ \\
\hline Threat/Harassment (141) & $12.7 \%$ & $12.8 \%$ & $12.7 \%$ & .01 \\
\hline Violence (135) & $23.0 \%$ & $24.1 \%$ & $21.6 \%$ & 1.16 \\
\hline Bereavement (130) & $85.9 \%$ & $85.5 \%$ & $86.4 \%$ & .27 \\
\hline Loved Ones Illness/Injury (136) & $55.9 \%$ & $51.2 \%$ & $62.0 \%$ & $15.93 * * *$ \\
\hline Others Death/Injury (138) & $24.0 \%$ & $29.4 \%$ & $17.2 \%$ & $27.41 * * *$ \\
\hline Social/Environmental Stress (135) & $42.7 \%$ & $39.6 \%$ & $46.5 \%$ & $6.55^{* *}$ \\
\hline Relationship Stress (133) & $40.9 \%$ & $38.9 \%$ & $43.5 \%$ & 3.04 \\
\hline Outcomes & $\begin{array}{l}\text { Overall } M \\
\quad(S D)\end{array}$ & Male $M(S D)$ & Female $M(S D)$ & $\mathrm{T}$ \\
\hline BRS & $4.49(1.21)$ & $4.68(1.15)$ & $4.26(1.24)$ & $-5.76 * * *$ \\
\hline HOPE & $2.93(.52)$ & $2.99(.50)$ & $2.85(.54)$ & $-4.51 * * *$ \\
\hline LOT & $3.25(.78)$ & $3.29(.74)$ & $3.20(.83)$ & -1.86 \\
\hline GSE & $5.16(1.18)$ & $5.29(1.11)$ & $5.00(1.23)$ & $-4.11 * * *$ \\
\hline
\end{tabular}

Note. LCA $=$ Latent Class Analysis; BRS $=$ Brief Resilience Scale; LOT $=$ Life Orientation Test; GSE = General Self-Efficacy; $* p<.05, * * p<.01, * * * p<.001 ;{ }^{*}=$ missing 24 . 
Table 2

Model Fit Statistics for all Latent Class Models Tested

\begin{tabular}{|c|c|c|c|c|c|c|c|c|}
\hline \multicolumn{9}{|l|}{ Study 1} \\
\hline Model & LL & AIC & CAIC & $\mathrm{BIC}$ & $\mathrm{ABIC}$ & ALMRT $(p)$ & $\operatorname{BLRT}(p)$ & Entropy \\
\hline 1-class & -1769.967 & 3555.935 & 3568.267 & 3586.753 & 3561.374 & $\mathrm{Na}$ & $\mathrm{Na}$ & $\mathrm{Na}$ \\
\hline 2-class & -1703.837 & 3441.674 & 3467.881 & 3507.161 & 3453.232 & 0.000 & 0.000 & 0.562 \\
\hline 3-class & -1683.664 & 3419.328 & 3459.409 & 3519.485 & 3437.004 & 0.002 & 0.000 & 0.787 \\
\hline 4-class & -1676.728 & 3423.457 & 3477.411 & 3558.284 & 3447.253 & 0.050 & 0.775 & 0.828 \\
\hline 5-class & -1670.012 & 3428.024 & 3495.854 & 3597.521 & 3457.939 & 0.191 & 0.840 & 0.854 \\
\hline 6-class & -1663.371 & 3432.741 & 3514.446 & 3636.908 & 3468.775 & 0.205 & 0.745 & 0.860 \\
\hline \multicolumn{9}{|l|}{ Study 2} \\
\hline 1-class & -6326.156 & 12668.312 & 12685.429 & 12710.145 & 12684.732 & $\mathrm{Na}$ & $\mathrm{Na}$ & $\mathrm{Na}$ \\
\hline 2-class & -5892.634 & 11819.269 & 11855.641 & 11908.164 & 11854.162 & 0.000 & 0.000 & 0.667 \\
\hline 3-class & -5805.008 & 11662.017 & 11717.645 & 11797.974 & 11715.382 & 0.000 & 0.000 & 0.704 \\
\hline 4-class & -5788.248 & 11646.495 & 11721.381 & 11829.514 & 11718.333 & 0.727 & 0.000 & 0.633 \\
\hline 5-class & -5772.175 & 11632.349 & 11726.491 & 11862.430 & 11722.660 & 0.462 & 0.000 & 0.593 \\
\hline 6-class & -5760.745 & 11627.490 & 11740.887 & 11904.633 & 11736.273 & 0.021 & 0.065 & 0.602 \\
\hline
\end{tabular}

Note. LL = Loglikelihood; AIC = Akaike Information Criteria; CAIC = Consistent AIC; BIC = Bayesian Information Criteria; ABIC = adjusted BIC; ALMRT = adjusted LoMendell Rubin Likelihood Ratio Test; BLRT = Bootstrap Likelihood Ratio Test; Boldface represents optimal fit. 
Table 3

Means and Mean-Level Class Difference of Outcome Variables in Study 1

\begin{tabular}{|c|c|c|c|c|c|}
\hline Reference Class & & Mean & High Polyad & Vicarious Ad & Low Polyad \\
\hline \multicolumn{6}{|l|}{ High Polyad } \\
\hline & BRS & $3.44(.13)$ & & 1.21 & 0.08 \\
\hline & HOPE & $4.14(.10)$ & & 0.78 & 0.43 \\
\hline & LOT & $3.58(.10)$ & & 0.95 & 2.15 \\
\hline & GSE & $4.14(.09)$ & & 0.32 & 0.29 \\
\hline \multicolumn{6}{|l|}{ Vicarious Ad } \\
\hline & BRS & $3.19(.16)$ & & & 2.23 \\
\hline & HOPE & $3.98(.14)$ & & & 0.19 \\
\hline & LOT & $3.38(.16)$ & & & $4.87 *$ \\
\hline & GSE & $4.03(.16)$ & & & 1.08 \\
\hline \multirow[t]{5}{*}{ Low Polyad } & & & Overall Test & & \\
\hline & BRS & $3.49(.12)$ & 2.28 & & \\
\hline & HOPE & $4.05(.09)$ & 0.83 & & \\
\hline & LOT & $3.80(.10)$ & 5.64 & & \\
\hline & GSE & $4.21(.09)$ & 1.17 & & \\
\hline
\end{tabular}

Note. Polyad = Polyadversity; Ad = Adversity; BRS = Brief Resilience Scale; LOT = Life Orientation Test; GSE $=$ General Self-Efficacy; $* p<.05, * * p<.01, * * * p<.001$; standard deviations are reported in brackets. 
Table 4

Means and Mean-Level Class Difference of Outcome Variables in Study 2

\begin{tabular}{|c|c|c|c|c|c|}
\hline Reference Class & & Mean & Low Polyad & Mod Polyad & High Polyad \\
\hline \multicolumn{6}{|l|}{ Low Polyad } \\
\hline & BRS & $4.41(.09)$ & & $5.05^{*}$ & $7.20 * *$ \\
\hline & HOPE & $2.95(.05)$ & & .40 & $8.80 * *$ \\
\hline & LOT & $3.20(.06)$ & & $4.31 *$ & $6.33^{*}$ \\
\hline & GSE & $5.13(.10)$ & & 1.98 & $5.93 *$ \\
\hline \multicolumn{6}{|l|}{ Mod Polyad } \\
\hline & BRS & $4.66(.06)$ & & & $22.58 * * *$ \\
\hline & HOPE & $2.98(.02)$ & & & $16.22 * * *$ \\
\hline & LOT & $3.36(.04)$ & & & $20.01 * * *$ \\
\hline & GSE & $5.29(.05)$ & & & $15.28 * * *$ \\
\hline \multirow[t]{5}{*}{ High Polyad } & & & Overall Test & & \\
\hline & BRS & $4.05(.10)$ & $22.67 * * *$ & & \\
\hline & HOPE & $2.75(.05)$ & $16.81 * * *$ & & \\
\hline & LOT & $2.98(.07)$ & $20.09 * * *$ & & \\
\hline & GSE & $4.77(.11)$ & $15.28 * * *$ & & \\
\hline
\end{tabular}




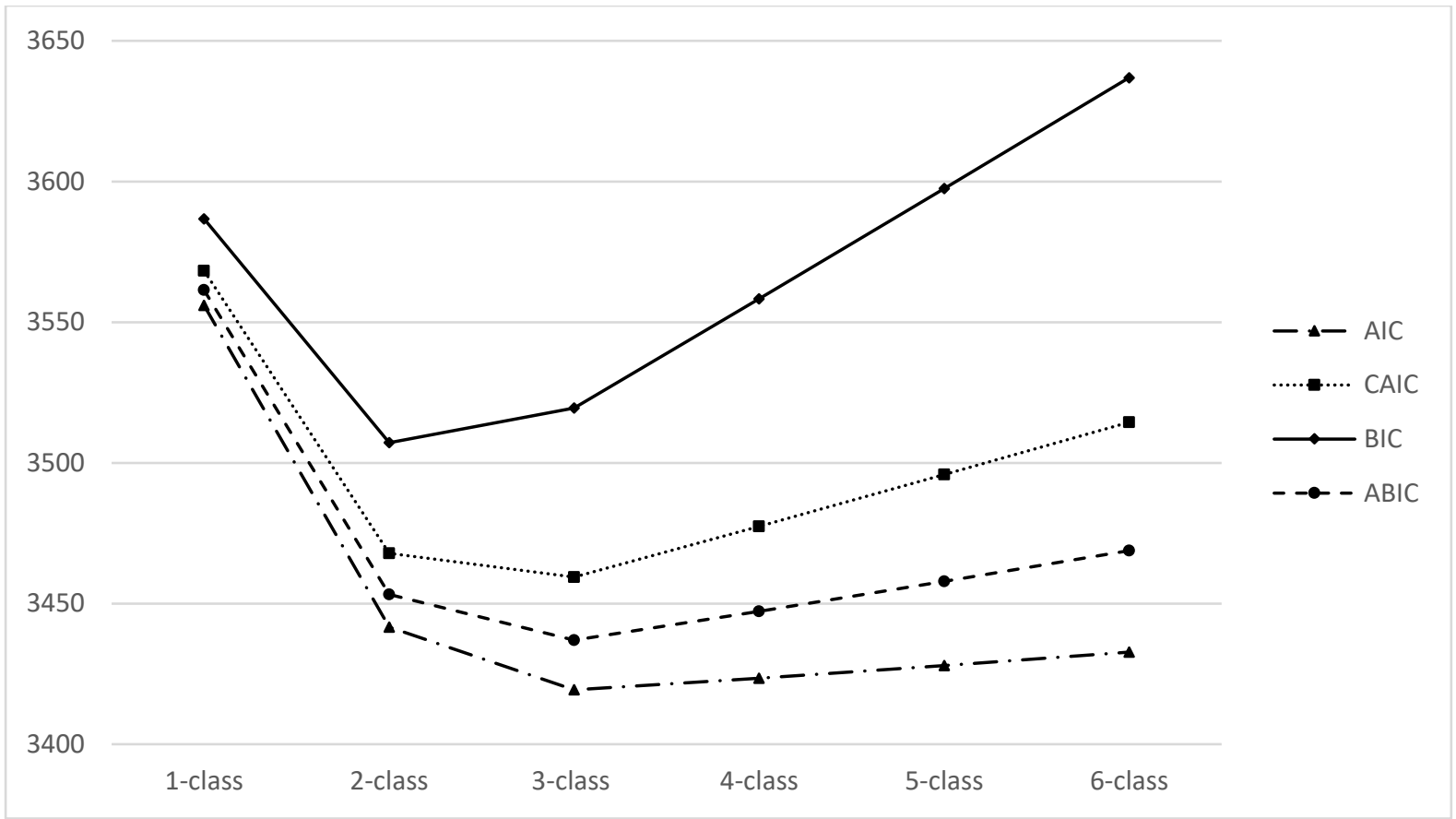

Note. $\mathrm{AIC}=$ Akaike's Information Criteria; $\mathrm{CAIC}=$ Consistent AIC; $\mathrm{BIC}=$ Bayesian Information Criteria; $\mathrm{ABIC}=$ adjusted $\mathrm{BIC}$.

Figure 1. Elbow plot of the information criteria for latent class models in Study 1 


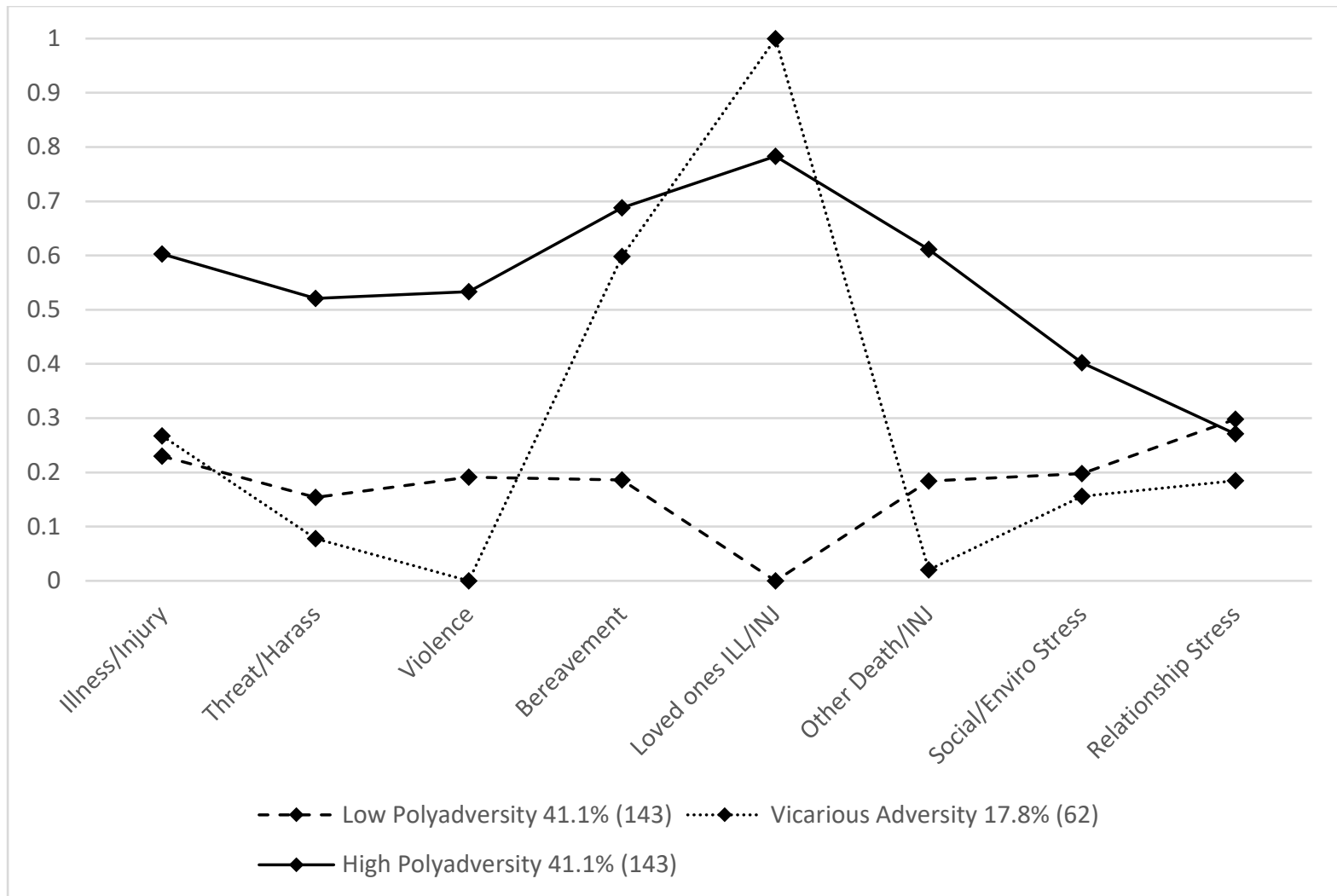

Note . Harass $=$ Harassment ILL = Illness; INJ = Injury; Enviro = Environmental.

Figure 2. Category probability plot of the three LTA classes in Study 1 


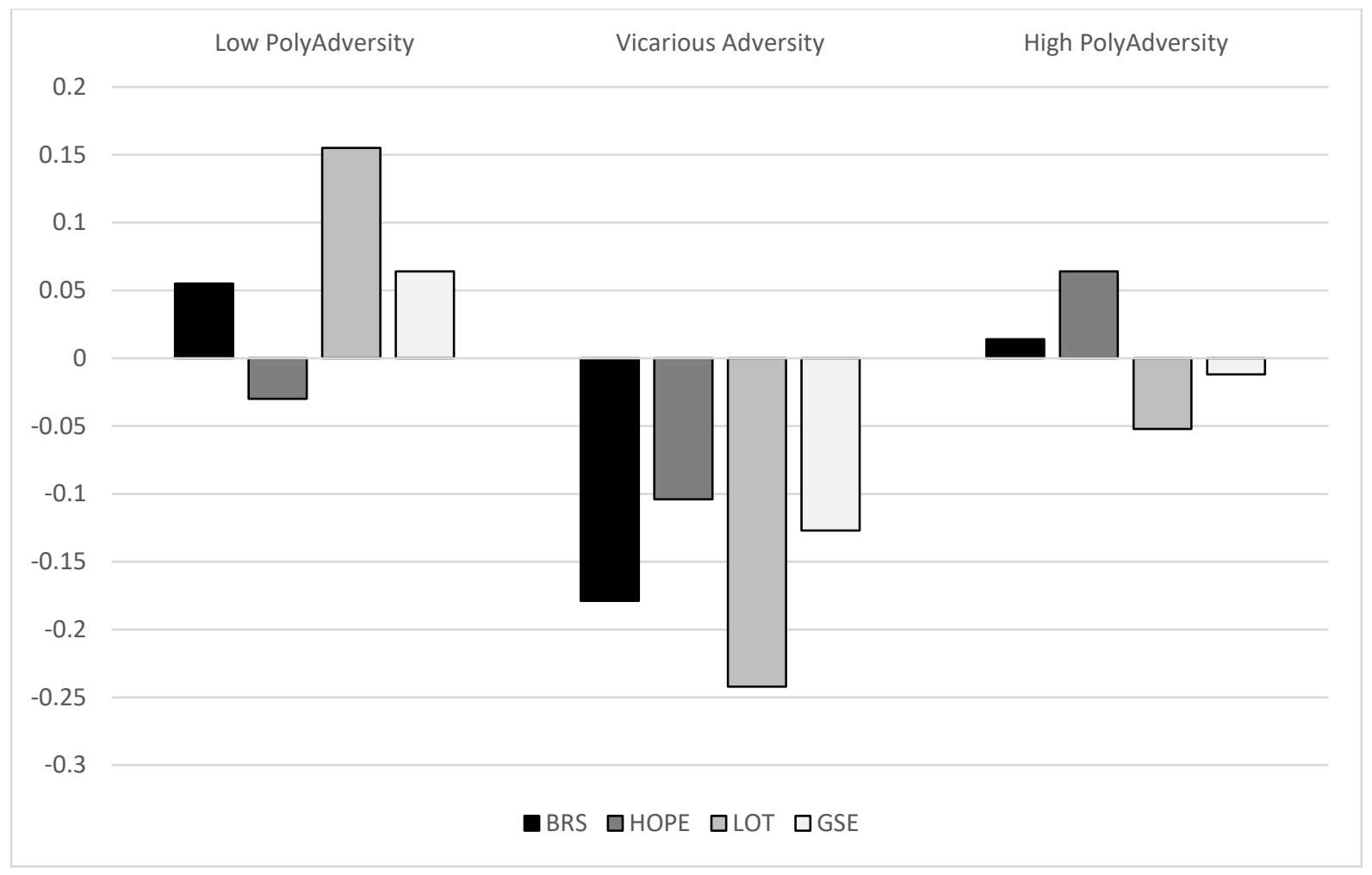

Note. BRS $=$ Brief Resilience Scale; LOT $=$ Life Orientation Test GSE $=$ General Self-Efficacy.

Figure 3. Standardised outcome variable scores across classes in Study 1 


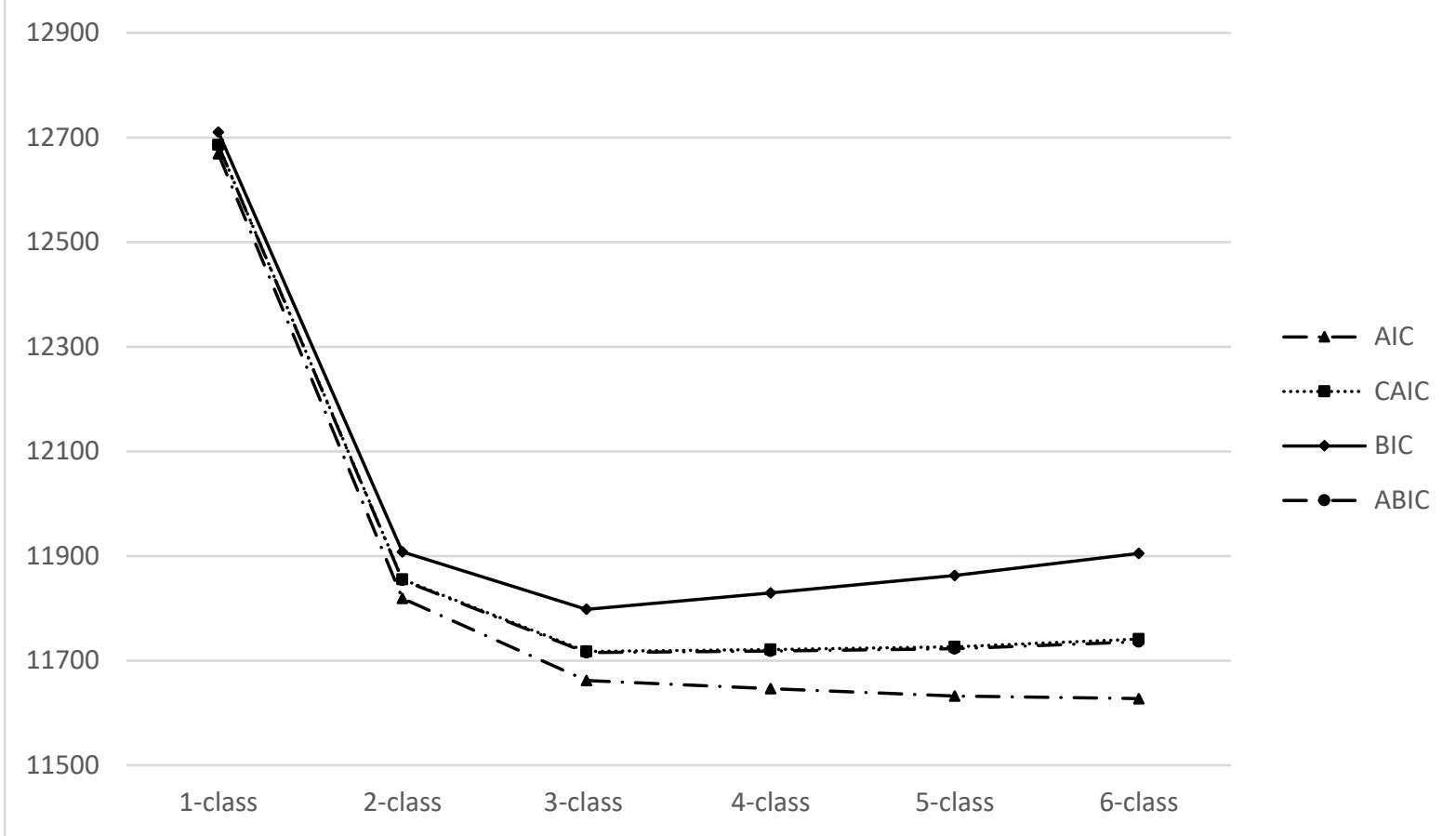

Note. AIC $=$ Akaike's Information Criteria; $\mathrm{CAIC}=$ Consistent AIC; BIC = Bayesian Information Criteria; $\mathrm{ABIC}=$ adjusted $\mathrm{BIC}$.

Figure 4. Elbow plot of the information criteria for latent class models in Study 2 


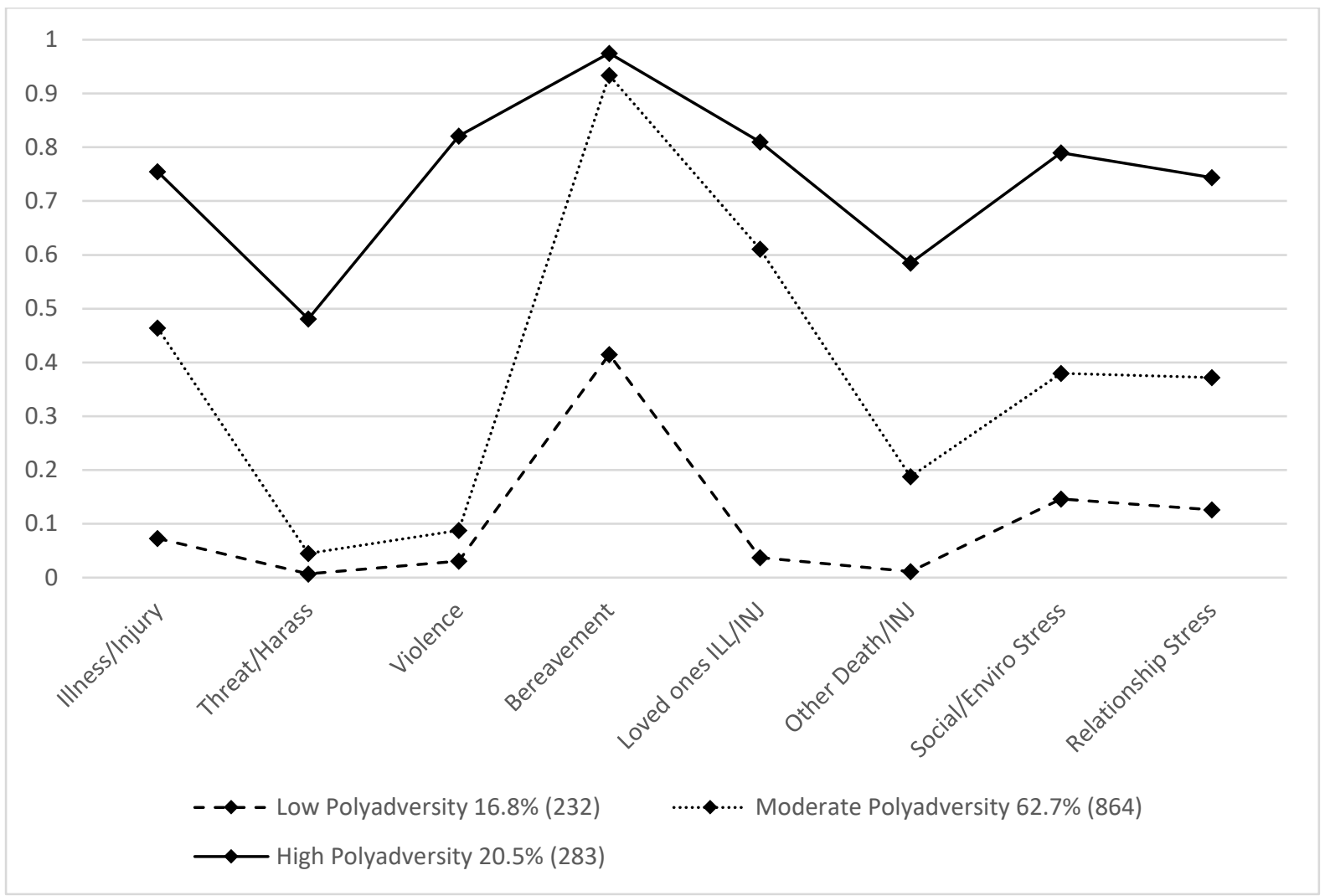

Note . Harass $=$ Harassment; ILL = Illness; INJ = Injury; Enviro = Environmental.

Figure 5. Category probability plot for the three LTA classes in Study 2 


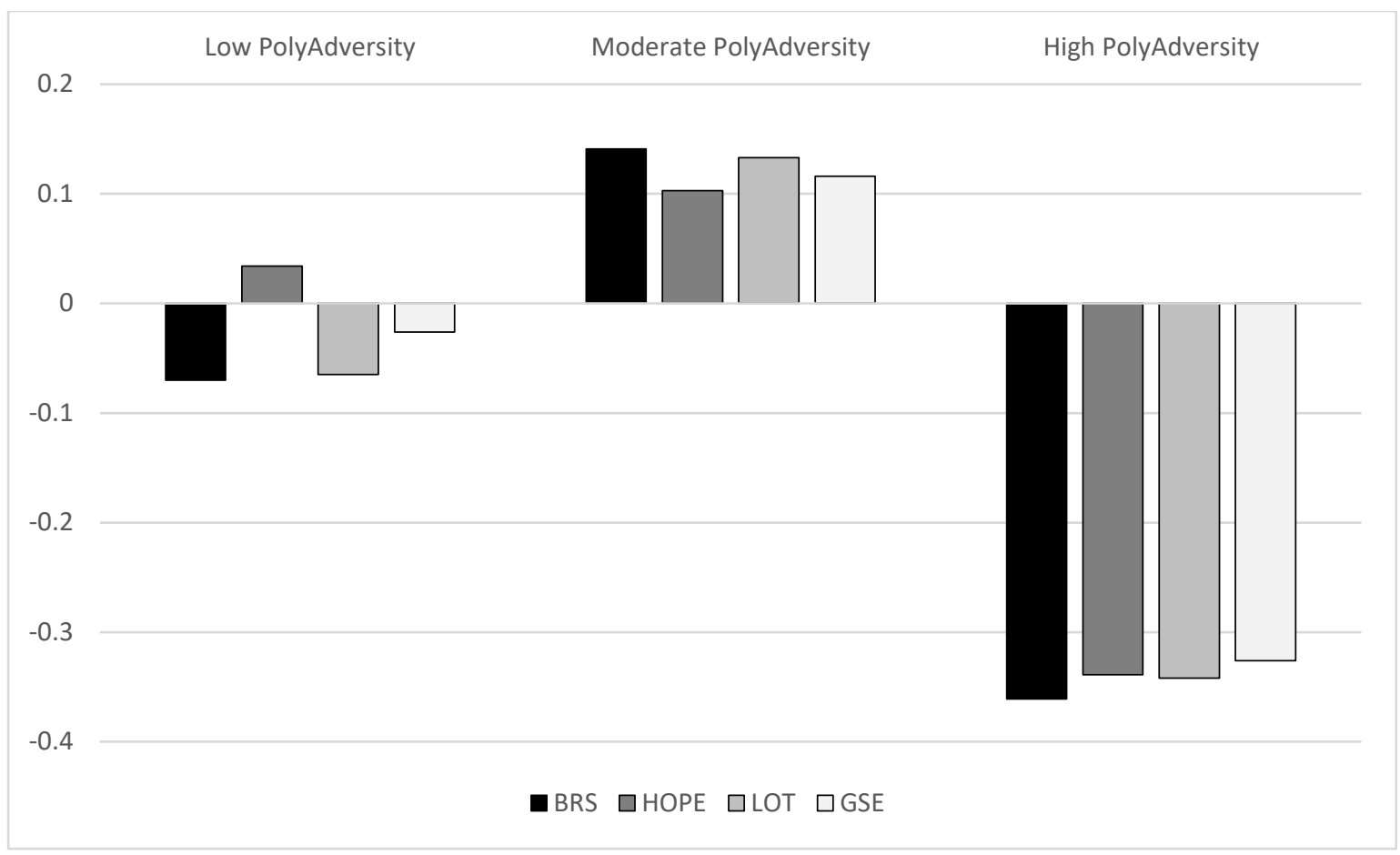

Note . BRS $=$ Brief Resilience Scale LOT $=$ Life Orientation Test GSE = General Self-Efficacy.

Figure 6. Standardised outcome variable scores across profiles in Study 2 